\title{
Allozyme analysis of geographical and seasonal variation of Illex coindetii (Cephalopoda: Ommastrephidae) from central Mediterranean and Iberian Atlantic
}

\author{
P. Martínez* ${ }^{\dagger}$, P. Belcari ${ }^{\dagger}$ A. Sanjuan* and A. Guerra ${ }^{\ddagger}$ \\ *Xenética Evolutiva Molecular, Facultade de Ciencias-Bioloxía, Universidade de Vigo, E-36200, Spain. \\ ${ }^{\dagger}$ Dipartamento Scienze Uomo e Ambiente, Universita di Pisa, 56126 Pisa, Italy. \\ ${ }^{\ddagger}$ ECOBIOMAR, Instituto de Investigaciones Marinas, CSIC, Eduardo Cabello, 6, Vigo, E-36208, Spain. \\ Present address and corresponding author: Instituto Nacional de Toxicología, Luis Cabrera 9, 28002 Madrid, Spain. \\ E-mail: pilarm.fernandez@mju.es
}

\begin{abstract}
Previous morphological studies of Illex coindetii from the Mediterranean have shown both juvenile and mature individuals all year round suggesting an homogeneous population pattern, however, seasonal spawning variation seems to exist varying with geographical area. Present work analysed 240 individuals from the northern Tyrrhenian and Atlantic Iberian waters at the four year-round seasons using 33 presumptive enzyme-coding loci to compare geographical and temporal variances. Genetic variability was low $\left(\mathrm{H}_{\mathrm{o}}=0.02-0.04\right)$. Moderate variation at some loci was found due to both temporal and geographical factors $\left(12 \%\right.$ of total genetic variance) and to temporal variance $\left(F_{S T}=0.004-0.015\right)$. Unweighted pair-group method using arithmetric averages (UPGMA) and Multidimensional scaling-minimum spanning tree (MDS-MST) analyses after Cavalli-Sforza \& Edwards (1967) chord genetic distances showed the summer Italian and the spring Atlantic samples as the most divergent among the whole.
\end{abstract}

\section{INTRODUCTION}

The species of Illicinae are likely to constitute a large portion $(59 \%)$ of the annual world ommastrephid squid catches (1.3 million tn; FAO, 1998). Illex coindetii (Vérany, 1837) represents a valuable resource due to its abundance in specific areas of the Mediterranean and Atlantic Ocean, where multiple studies on its life cycle characteristics have been conducted (Sánchez et al., 1998). The species plays an important role in marine food webs providing prey items for demersal predators (Sánchez et al., 1998). However, information on the biology of $I$. coindetii throughout its distribution range, especially within the central Mediterranean waters, has been scarce (e.g. Belcari, 1996) and thorough research of its population structure is needed.

Previous analysis of length-frequency distributions for I. coindetii samples from western and central Mediterranean showed no evidence for the existence of distinct spawning populations (Belcari, 1996; González \& Guerra, 1996; Sánchez et al., 1998). However, based on morphological analysis, some seasonal peaks of spawners individuals seem to exist and they may vary with geographical area (González \& Guerra, 1996; Sánchez et al., 1998). Thus, individuals had a major peak in autumn (Sánchez et al., 1998), and in spring and summer at the Mediterranean and Iberian Atlantic, respectively (González \& Guerra, 1996). Moreover, previous morphological studies had shown geographical variation in spite of no conclusive result in the population structure of $I$. coindetii throughout the Mediterranean and Atlantic waters (HernándezGarcía \& Castro, 1998; Sánchez et al., 1998). Genetic information of the species may provide a valuable contribution to a better understanding on the degree to which species are subdivided into effective populations or stocks, which is one of the most fundamental problems in any fishery (Sánchez et al., 1998).

There is a lack of genetic studies on Mediterranean versus Atlantic populations within ommastrephids. The analysis of geographical structure by electrophoretic characterization of allelic isozymes has been successful for other cephalopods (Maltagliati et al., 2002; Yeatman \& Benzie, 1993), and particularly for other Illex species (Carvalho et al., 1992).

Temporal genetic population analysis has proved to be fruitful for objective stock identification on migrating teleosts (e.g. Waples \& Teel, 1990) although this time-variable research has been absent for cephalopods. Many allozyme studies on marine populations have compared their genetic structure from different locations, under the assumption that the protein variation was temporally homogeneous and therefore geographically comparable (Moffett \& Crozier, 1996). The present paper is aimed to evaluate potential geographic differentiation among populations of $I$. coindetii inhabiting the Tyrrhenian Sea and Iberian Atlantic waters, and to assess temporal stability of the allele frequencies out of 33 enzyme-coding loci from simultaneously captured samples through seasons within a year.

\section{MATERIALS AND METHODS}

\section{Sampling}

Sample codes, sampling areas, seasons and number of specimens per sample are shown in Table 1. Samples were freshly caught at local fishing auctions at Ribeira (north- 
Table 1. Sample codes, sampling area, sampling season and number of individuals $(\mathcal{N})$ of analysed Illex coindetii.

\begin{tabular}{llll}
\hline Code & Sampling Area & Season & N \\
\hline IcW-W & NW Iberian Atlantic & Winter & 22 \\
IcP-W & Pisa, Tyrrhenian Sea & Winter & 19 \\
IcW-Sp & NW Iberian Atlantic & Spring & 32 \\
IcP-Sp & Pisa, Tyrrhenian Sea & Spring & 33 \\
IcW-Sum & NW Iberian Atlantic & Summer & 33 \\
IcP-Sum & Pisa, Tyrrhenian Sea & Summer & 39 \\
IcW-Aut & NW Iberian Atlantic & Autumn & 26 \\
IcP-Aut & Pisa, Tyrrhenian Sea & Autumn & 36 \\
\hline
\end{tabular}

western Iberian Atlantic coast) and Pisa (northernTyrrhenian Sea, Italy) by bottom-trawlers. Over time sampling for the four seasons (1997-1998) analysis within each area was obtained simultaneously. Collected Illex coindetii individuals were both juvenile and mature and completed the one-year life cycle of the species, what excluded the possibility to have sampled different cohorts as it would be the case for teleost species. Specimens were kept at $-20^{\circ} \mathrm{C}$ while shipping to the laboratory where they were deepfrozen at $-80^{\circ} \mathrm{C}$ until processing. A total of 240 individuals were analysed by allozyme starch-gel electrophoresis.

\section{Electrophoresis procedure}

Horizontal starch-gel electrophoresis was carried out based on Murphy et al. (1996). A piece $(11 \times 11 \mathrm{~mm})$ of mantle muscle was sliced out for homogenization with
$0.01 \mathrm{M}$ dithiothreitol (DTT) solution. The homogenate was centrifuged at $12,000 \mathrm{~g}$ for $10 \mathrm{~min}$ at $4^{\circ} \mathrm{C}$ and the supernatant was embedded in Whatman strips no. 2 and 3. Hydrolysed-starch gels (12\%, SIGMA starch) were run at constant voltage at $4{ }^{\circ} \mathrm{C}$. Enzyme systems routinely examined with adequate activity and resolution were shown in Table 2. The Tris-citrate, $\mathrm{pH} 8.0$ buffer system (gel buffer dilution 1:11) was used for most of the enzymes (at $4.6 \mathrm{Vcm}^{-1}$ ) except for ADA, G6PDH and GPI where Tris-borate-EDTA, 8.7 buffer was used (gel buffer dilution 1:9 for ADA with $3.6 \mathrm{Vcm}^{-1}$ and 1:5 for G6PDH and GPI with $10 \mathrm{Vcm}^{-1}$ ) and for MEP and the locus OPDH-3* where citrate morpholine, $\mathrm{pH} 7.4$ buffer was employed. These enzymes were stained according to recipes in Murphy et al. (1996), with some variations for AAT, ACP, DDH, ESTD, IDHP, LAP, MPI, PEPA, PEPB, PEPD, PGDH, PGM, PK (e.g. Harris \& Hopkinson, 1976). The 26 enzymes resolved 33 putative enzyme-coding loci.

Table 2. Enzyme systems analysed with respective enzyme codes (E.C.).

\begin{tabular}{|c|c|}
\hline Enzyme system & E.C. \\
\hline Aspartate Transaminase & AAT; 2.6.1.1. \\
\hline Acid Phosphatase & ACP; 3.1.3.2. \\
\hline Adenosine Deaminase & $\mathrm{ADA} ; 3.5 .4 .4$. \\
\hline Adenylate Kinase & $\mathrm{AK} ; 2.7 .4 .3$ \\
\hline Alanopine Dehydrogenase & ALPDH; 1.5.1.17. \\
\hline Arginine Kinase & ARK; 2.7.3.3. \\
\hline Hihydrolipoamide Transaminase & $\mathrm{DDH} ; 1.8 .1 .4$. \\
\hline Carboxylic Ester Hydrolase (substrate: a-naphthyl acetate) & EST; 3.1.1.-. \\
\hline Methylumbelliferyl-acetate Deacetylase & ESTD; 3.1.1.56. \\
\hline Glycerol-3-phosphate Dehydrogenase $\left(\mathrm{NAD}^{+}\right)$ & G3PDH; 1.1.1.8. \\
\hline Glucose-6-phosphate Dehydrogenase & G6PDH; 1.1.1.49. \\
\hline Glyceraldehyde-3-phosphate Dehydrogenase, phosphorylating & GAPDH; 1.2 .1 .12 \\
\hline Glucose-6-phosphate isomerase & GPI; 5.3.1.9. \\
\hline L-Iditol 2-dehydrogenase & IDDH; 1.1.1.14. \\
\hline Isocitrate Dehydrogenase $\left(\mathrm{NADP}^{+}\right)$ & IDHP; 1.1.1.42. \\
\hline L-Leucyl Aminopeptidase & LAP; 3.4.11.1. \\
\hline Malate Dehydrogenase & $\mathrm{MDH} ; 1.1 .1 .37$. \\
\hline Malate Dehydrogenase (oxaloacetate-decarboxylating) $\left(\mathrm{NADP}^{+}\right)$ & MEP; 1.1.1.40. \\
\hline Mannose-6-phosphate Iisomerase & MPI; 5.3.1.8. \\
\hline D-Octopine Dehydrogenase & OPDH; 1.5.1.11. \\
\hline Cytosol non-specific Dipeptidase; substrate: gly-leu & PEPA; 3.4.13.18. \\
\hline Tripeptide Aminopeptidase; substrate: leu-gly-gly & PEPB; 3.4.11.4. \\
\hline X-pro Dipeptidase; substrate: phe-pro & PEPD; 3.4.13.9. \\
\hline Phosphogluconate Dehydrogenase (decarboxylating) & PGDH; 1.1.1.44. \\
\hline Phosphoglucomutase & PGM; 5.4.2.2. \\
\hline Pyruvate Kinase & $\mathrm{PK} ; 2.7 .1 .40$. \\
\hline Superoxide Dismutase & SOD; 1.15.1.1. \\
\hline
\end{tabular}




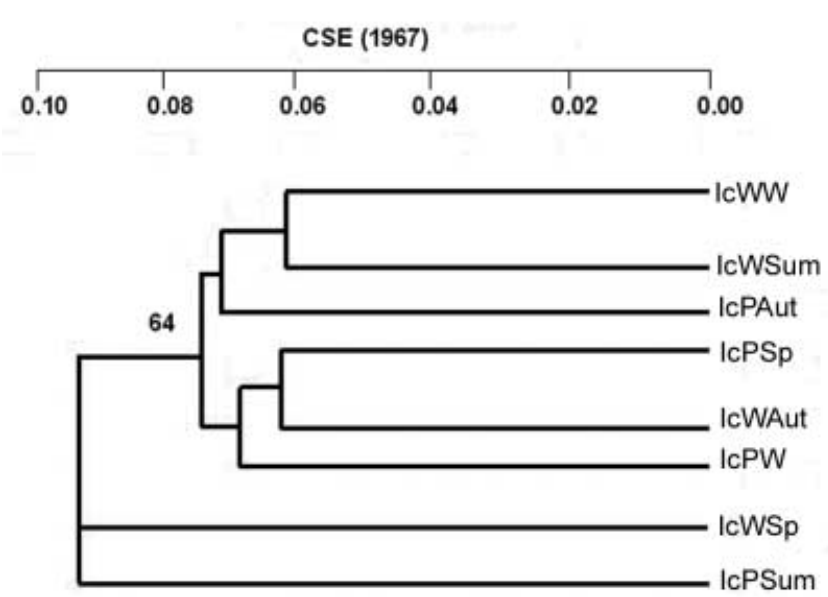

Figure 1. UPGMA dendogram based on Cavalli-Sforza \& Edward's (1967) chord (CSE) genetic distances for Illex coindetii samples off north-western Iberian and Pisa (IcW, IcP) waters in winter (W), spring (Sp), summer (Sum) and autumn (Aut) seasons. The number at the node indicates the percentage occurrence after 100 replicates. Sample codes are indicated in Table 1 .

Banding patterns of the presumptive loci were interpreted according to the current subunit structure of each enzyme. Notations for allozymes are based on recommendations by IUBMB (1992). Arabic numerical suffixes for multiple loci $(1,2, .$.$) and for alleles (* 100, * 105, .$.$) are presented in order$ of decreasing and increasing anodal mobility, respectively, where the allele $* 100$ corresponded to the most frequent.

\section{Data analysis}

Genotype frequencies at polymorphic loci were tested for agreement with Hardy-Weinberg (HW) expectations by chi-squared tests, and the probability of the null hypothesis was estimated using the Markov chain method (Guo \& Thompson, 1992). Mean expected heterozygosity $\left(\mathrm{H}_{\mathrm{e}}\right)$ per locus (unbiased estimate), observed heterozygosity $\left(\mathrm{H}_{\mathrm{o}}\right)$, mean number of alleles $\left(\mathrm{N}_{\mathrm{a}}\right)$ and proportion of polymorphic loci $\mathrm{P}_{95}$ (Nei, 1987) were calculated for each sample. Arcsine square-root transformations of $\mathrm{H}_{\mathrm{e}}$ were compared among samples by $t$-test analysis (Sokal \& Rohlf, 1981). One level-hierarchical analysis of gene diversity (Wright, 1978) was carried out for seasons nested within each locality. $F$-statistic estimates after 2000 permutations were tested relying on log-likelihood Gstatistics by FSTAT (Goudet, 1995). The statistic $F_{\text {IS }}$ was computed for HW variation within samples being alleles permuted among individuals by FSTAT. The significance of $F_{\mathrm{ST}}$ for the temporal comparisons was assessed using the chi-squared test of Workman \& Niswander (1970) (Sokal \& Rohlf, 1981). Wherever significance testing occurred, Bonferroni's procedures were employed to eliminate false significance assignment by chance (Rice, 1989). Waples' (1989) correction for the temporal variation analysis was not appropriate due to the presence of loci with more than three alleles within samples of $\mathrm{N}<80$ individuals. Cavalli-Sforza \& Edwards' (1967) chord $\left(D_{\text {cho }}\right)$ genetic distance among samples was computed (PHYLIP; Felsenstein, 1993) and UPGMA analysis and

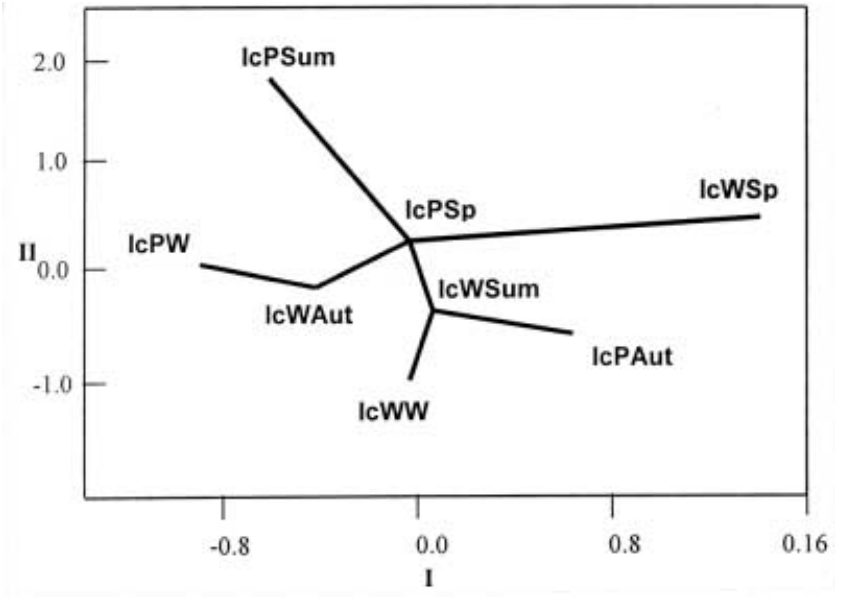

Figure 2. MDS plot superimposed by the multidimensional spanning tree (MST) based on Cavalli-Sforza \& Edward's (1967) chord genetic distances for Illex coindetii populations off north-western Iberian and Pisa $(\mathrm{IcW}, \mathrm{IcP})$ waters in winter (W), spring (Sp), summer (Sum) and autumn (Aut) seasons. Stress coefficient was $S=0.0877$. Sample codes are indicated in Table 1.

non-metric multidimensional scaling (nMDS) (Kruskal, 1964), superimposed by a minimum-spanning tree (MST), were performed from $\mathrm{D}_{\text {cho }}$ data. Bootstrapped values for the UPGMA were computed after 100 tree replicates using PHYLIP.

\section{RESULTS \\ Genetic variability}

Allele frequencies at 23 polymorphic enzyme-coding loci are shown in Table 3. Ten loci out of 33 were monomorphic in most samples analysed (AAT-1*, AAT-2*, $A R K^{*}, G A P D H^{*}, G P I-1^{*}, \mathrm{GPI}-2^{*}, M D H-2 *, M P I-1^{*}$, $\left.P K^{*}, S O D^{*}\right)$, while 11 loci showed one or two rare alleles (allele frequency $<0.05$ ), and 12 loci exhibited a moderate variability with 2,3 or more alleles (up to 6) per locus $\left(A C P^{*}, A L P D H^{*}, E S T^{*}, G 3 P D H^{*}, G 6 P D H^{*}, I D D H^{*}\right.$, $\left.I D H P-1^{*}, I D H P-2^{*}, M D H-1^{*}, O P D H-3 *, P G D H^{*}, P G M^{*}\right)$.

Heterozygosities $\left(\mathrm{H}_{\mathrm{o}}, \mathrm{H}_{\mathrm{e}}\right)$, average number of alleles per locus $\left(\mathrm{N}_{\mathrm{a}}\right)$ and $95 \%$ polymorphism $\left(\mathrm{P}_{95}\right)$ indicated general low to moderate values for all samples analysed (Table 3). Significant differences between observed heterozygosities was found for IcPSum vs IcWSum $(t=2.042$, $P<0.05)$ and IcPSum vs IcWAut $(t=2.457, P<0.05)$. Values from the winter and spring individuals of the Atlantic $\left(\mathrm{H}_{\mathrm{o}}=0.035\right.$ and 0.031 , respectively) were higher than in the summer and autumn populations $\left(\mathrm{H}_{\mathrm{o}}<0.021\right)$, and generally less variable in Italian waters $\left(\mathrm{H}_{\mathrm{o}}=0.020-\right.$ 0.025 ) except for the summer sample. However, heterozygosity variations were only significant if considering the Italian combination $(t=3.365, P<0.005) ; \mathrm{N}_{\mathrm{a}}$ was lower than 1.5 for all analysed populations (1.21-1.48) except for the summer IcPSum $\left(\mathrm{N}_{\mathrm{a}}=1.73 \pm 0.13\right)$ and spring Iberian samples $\left(\mathrm{N}_{\mathrm{a}}=1.58 \pm 0.12\right)$. Similarly, $95 \%$ polymorphism was highest for the summer Italian and spring Iberian populations, both reaching $\mathrm{P}_{95}=0.15$ (Table 3). The $F$-values between loci and populations showed no significant deviation from HW expectations apart from the summer Italian individuals at $P G M^{*}$ locus, and the 
Table 3. Allele frequencies at 33 loci, sample sizes $(\mathcal{N})$ and genetic variability indices: $H_{e}(S E)$ unbiased estimate of mean expected heterozygosity; $H_{0}(S E)$ mean observed heterozygosity; $\mathcal{N}_{a}(S E)$ mean number of alleles; and $P_{95}$, polymorphism to the $95 \%$ criteria) for Illex coindetii populations off north-western Iberian and Tyrrhenian Sea (IcW, IcP) waters in winter (W), spring (Sp), summer (Sum) and autumn (Aut) seasons. Sample codes are indicated in Table 1.

\begin{tabular}{|c|c|c|c|c|c|c|c|c|}
\hline \multirow[b]{2}{*}{ Locus } & \multicolumn{8}{|c|}{ Population } \\
\hline & IcW-W & IcP-W & IcW-Sp & IcP-Sp & IcW-Sum & IcP-Sum & IcW-Aut & IcP-Aut \\
\hline \multicolumn{9}{|l|}{$A C P^{*}$} \\
\hline$(\mathrm{N})$ & 20 & 19 & 32 & 32 & 31 & 36 & 26 & 35 \\
\hline$* 90$ & 0.050 & 0.079 & 0.000 & 0.031 & 0.016 & 0.028 & 0.096 & 0.029 \\
\hline *100 & 0.950 & 0.921 & 0.984 & 0.969 & 0.952 & 0.931 & 0.865 & 0.971 \\
\hline *105 & 0.000 & 0.000 & 0.000 & 0.000 & 0.000 & 0.028 & 0.000 & 0.000 \\
\hline *110 & 0.000 & 0.000 & 0.000 & 0.000 & 0.032 & 0.000 & 0.000 & 0.000 \\
\hline *115 & 0.000 & 0.000 & 0.016 & 0.000 & 0.000 & 0.014 & 0.038 & 0.000 \\
\hline \multicolumn{9}{|l|}{$A D A^{*}$} \\
\hline$(\mathrm{N})$ & 20 & 19 & 17 & 15 & 10 & 38 & 26 & 24 \\
\hline$* 80$ & 0.000 & 0.000 & 0.000 & 0.000 & 0.000 & 0.000 & 0.000 & 0.021 \\
\hline$* 100$ & 1.000 & 1.000 & 1.000 & 1.000 & 1.000 & 1.000 & 1.000 & 0.979 \\
\hline \multicolumn{9}{|l|}{$A K^{*}$} \\
\hline$(\mathrm{N})$ & 20 & 19 & 17 & 20 & 27 & 37 & 20 & 24 \\
\hline$* 80$ & 0.000 & 0.000 & 0.000 & 0.000 & 0.000 & 0.014 & 0.000 & 0.000 \\
\hline *100 & 1.000 & 1.000 & 1.000 & 1.000 & 1.000 & 0.986 & 1.000 & 1.000 \\
\hline \multicolumn{9}{|l|}{$A L P D H^{*}$} \\
\hline$(\mathrm{N})$ & 20 & 19 & 32 & 32 & 31 & 36 & 16 & 34 \\
\hline *35 & 0.000 & 0.000 & 0.000 & 0.000 & 0.000 & 0.000 & 0.000 & 0.015 \\
\hline$* 90$ & 0.000 & 0.000 & 0.031 & 0.016 & 0.000 & 0.000 & 0.000 & 0.015 \\
\hline *95 & 0.000 & 0.000 & 0.000 & 0.016 & 0.016 & 0.000 & 0.000 & 0.000 \\
\hline$* 100$ & 0.975 & 1.000 & 0.953 & 0.953 & 0.968 & 0.917 & 0.969 & 0.956 \\
\hline *105 & 0.025 & 0.000 & 0.000 & 0.016 & 0.016 & 0.042 & 0.031 & 0.015 \\
\hline *110 & 0.000 & 0.000 & 0.016 & 0.000 & 0.000 & 0.042 & 0.000 & 0.000 \\
\hline \multicolumn{9}{|l|}{$D D H^{*}$} \\
\hline$(\mathrm{N})$ & 22 & 19 & 29 & 28 & 28 & 35 & 26 & 31 \\
\hline$* 60$ & 0.000 & 0.000 & 0.000 & 0.000 & 0.000 & 0.014 & 0.000 & 0.000 \\
\hline$* 100$ & 1.000 & 1.000 & 1.000 & 1.000 & 1.000 & 0.986 & 1.000 & 1.000 \\
\hline \multicolumn{9}{|l|}{$E S T^{*}$} \\
\hline$(\mathrm{N})$ & 20 & 10 & 28 & 27 & 16 & 33 & 22 & 28 \\
\hline *95 & 0.000 & 0.000 & 0.036 & 0.019 & 0.000 & 0.000 & 0.000 & 0.000 \\
\hline$* 100$ & 0.975 & 1.000 & 0.964 & 0.981 & 1.000 & 0.909 & 1.000 & 1.000 \\
\hline *105 & 0.025 & 0.000 & 0.000 & 0.000 & 0.000 & 0.000 & 0.000 & 0.000 \\
\hline *110 & 0.000 & 0.000 & 0.000 & 0.000 & 0.000 & 0.091 & 0.000 & 0.000 \\
\hline \multicolumn{9}{|l|}{ ESTD* } \\
\hline$(\mathrm{N})$ & 20 & 19 & 25 & 32 & 32 & 38 & 26 & 34 \\
\hline *95 & 0.000 & 0.000 & 0.000 & 0.000 & 0.000 & 0.013 & 0.000 & 0.000 \\
\hline$* 100$ & 1.000 & 1.000 & 1.000 & 1.000 & 1.000 & 0.987 & 1.000 & 1.000 \\
\hline \multicolumn{9}{|l|}{$G 3 P D H^{*}$} \\
\hline$(\mathrm{N})$ & 18 & 15 & 20 & 31 & 8 & 33 & 25 & 27 \\
\hline$* 90$ & 0.000 & 0.000 & 0.025 & 0.000 & 0.000 & 0.000 & 0.000 & 0.074 \\
\hline$* 100$ & 1.000 & 1.000 & 0.925 & 0.984 & 1.000 & 0.970 & 1.000 & 0.926 \\
\hline *110 & 0.000 & 0.000 & 0.000 & 0.016 & 0.000 & 0.030 & 0.000 & 0.000 \\
\hline *120 & 0.000 & 0.000 & 0.050 & 0.000 & 0.000 & 0.000 & 0.000 & 0.000 \\
\hline \multicolumn{9}{|l|}{$G 6 P D H^{*}$} \\
\hline$(\mathrm{N})$ & 22 & 17 & 26 & 24 & 28 & 31 & 26 & 28 \\
\hline$* 60$ & 0.023 & 0.000 & 0.000 & 0.000 & 0.000 & 0.000 & 0.000 & 0.000 \\
\hline$* 80$ & 0.045 & 0.000 & 0.038 & 0.021 & 0.018 & 0.016 & 0.000 & 0.000 \\
\hline$* 90$ & 0.000 & 0.000 & 0.000 & 0.000 & 0.000 & 0.081 & 0.000 & 0.018 \\
\hline$* 100$ & 0.932 & 1.000 & 0.962 & 0.979 & 0.982 & 0.903 & 1.000 & 0.982 \\
\hline \multicolumn{9}{|l|}{$I D D H^{*}$} \\
\hline$(\mathrm{N})$ & 22 & 18 & 30 & 24 & 32 & 37 & 26 & 34 \\
\hline$* 60$ & 0.000 & 0.028 & 0.033 & 0.062 & 0.016 & 0.027 & 0.000 & 0.000 \\
\hline$* 100$ & 0.977 & 0.944 & 0.950 & 0.938 & 0.953 & 0.973 & 0.981 & 0.985 \\
\hline *105 & 0.000 & 0.028 & 0.000 & 0.000 & 0.000 & 0.000 & 0.019 & 0.000 \\
\hline$* 110$ & 0.000 & 0.000 & 0.000 & 0.000 & 0.000 & 0.000 & 0.000 & 0.015 \\
\hline *120 & 0.023 & 0.000 & 0.017 & 0.000 & 0.031 & 0.000 & 0.000 & 0.000 \\
\hline \multicolumn{9}{|l|}{$I D H P-1 *$} \\
\hline$(\mathrm{N})$ & 20 & 19 & 31 & 31 & 31 & 38 & 26 & 33 \\
\hline$* 90$ & 0.050 & 0.000 & 0.000 & 0.000 & 0.000 & 0.000 & 0.000 & 0.000 \\
\hline *100 & 0.950 & 0.947 & 0.984 & 1.000 & 1.000 & 0.961 & 1.000 & 1.000 \\
\hline *105 & 0.000 & 0.000 & 0.000 & 0.000 & 0.000 & 0.013 & 0.000 & 0.000 \\
\hline
\end{tabular}


Table 3. (Continued).

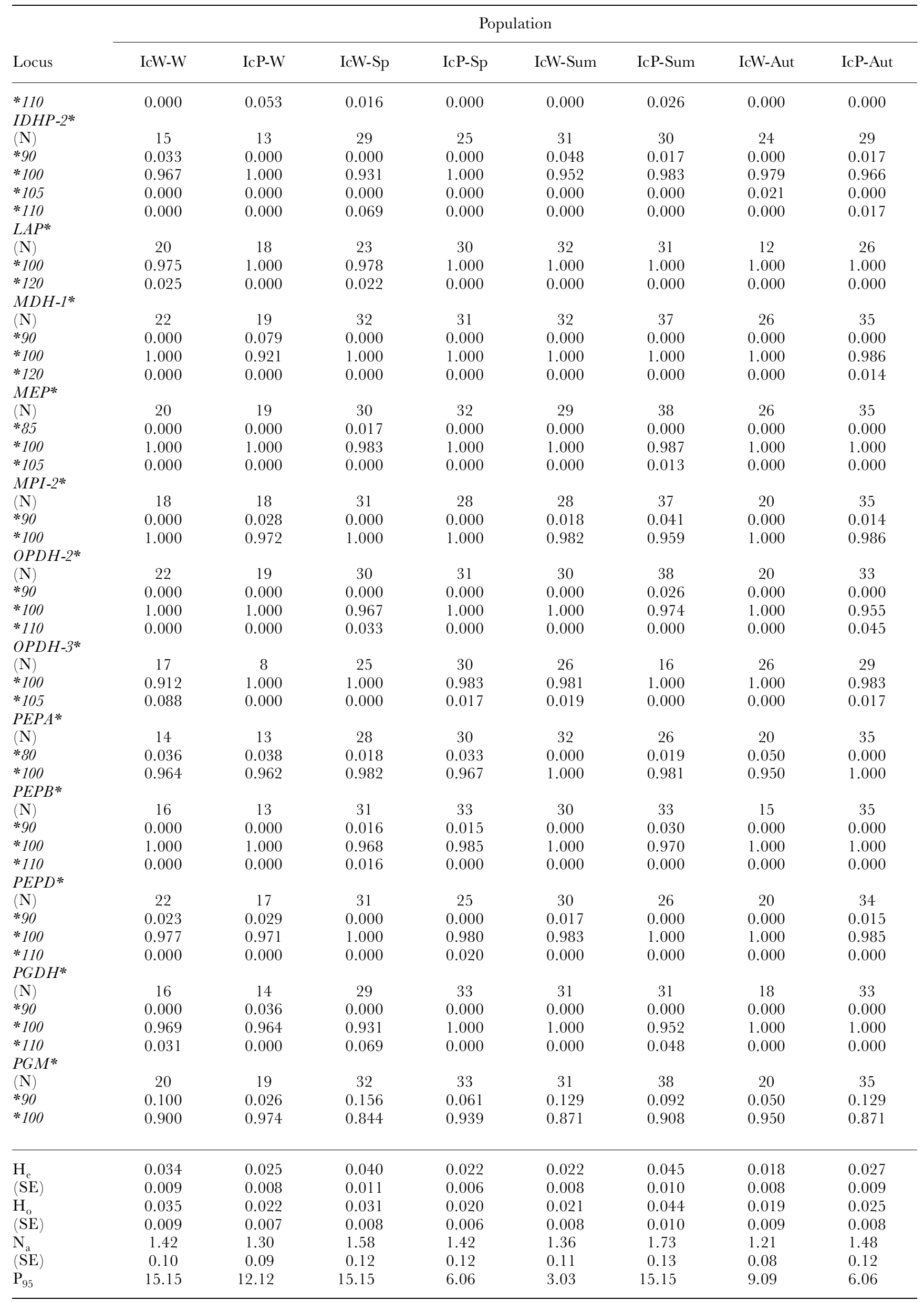


Table 4. Nei's (1987) unbiased F-statistic estimates $\left(\mathrm{F}_{I S}\right.$ and $\left.\mathrm{F}_{S T}\right)$ for geographic (Tyrrhenian versus Atlantic) and temporal (Winter, Spring, Summer and Autumn) population differentiation of Illex coindetii. Differentiation at G6PDH*, MDH-1*, $P G H D *$ and $G 3 P D H^{*}$ loci was significant $(\mathrm{P}<0.05)$ after log-likelihood $G$-statistic testing within geographical, winter, spring and autumn comparisons, respectively.

\begin{tabular}{|c|c|c|c|c|c|c|c|c|c|c|}
\hline \multirow[b]{2}{*}{ Locus } & \multicolumn{2}{|c|}{ Geographic } & \multicolumn{2}{|c|}{ Winter } & \multicolumn{2}{|c|}{ Spring } & \multicolumn{2}{|c|}{ Summer } & \multicolumn{2}{|c|}{ Autumn } \\
\hline & $F_{\text {IS }}$ & $F_{\mathrm{ST}}$ & $F_{\text {IS }}$ & $F_{\mathrm{ST}}$ & $F_{\text {IS }}$ & $F_{\mathrm{ST}}$ & $F_{\text {IS }}$ & $F_{\mathrm{ST}}$ & $F_{\text {IS }}$ & $F_{\mathrm{ST}}$ \\
\hline & -0.039 & -0.002 & -0.046 & -0.018 & -0.001 & 0.000 & -0.040 & -0.002 & -0.098 & 0.024 \\
\hline $\begin{array}{l}\mathbf{A C P} * \\
A D A^{*}\end{array}$ & 0.001 & -0.001 & & & & & & & -0.016 & 0007 \\
\hline$A K^{*}$ & 0.000 & 0.000 & & & & & -0.009 & -0.001 & & \\
\hline$A L P D H^{*}$ & 0.026 & -0.003 & 0.001 & -0.001 & 0.153 & -0.013 & -0.050 & 0.003 & -0.026 & -0.001 \\
\hline$D D H^{*}$ & 0.000 & 0.000 & & & & & -0.009 & -0.001 & & \\
\hline$E S T^{*}$ & -0.021 & 0.008 & 0.013 & -0.014 & -0.012 & -0.013 & -0.109 & -0.046 & & \\
\hline$E S T D^{*}$ & 0.000 & 0.000 & & & & & -0.007 & 0.005 & & \\
\hline$G 3 P D H^{*}$ & 0.249 & -0.001 & & & 0.540 & 0.007 & -0.026 & 0.012 & -0.075 & 0.034 \\
\hline$G 6 P D H^{*}$ & -0.025 & 0.004 & -0.029 & 0.028 & -0.013 & -0.015 & -0.073 & -0.002 & -0.013 & 0.005 \\
\hline$I D D H^{*}$ & -0.023 & -0.001 & -0.012 & -0.005 & -0.036 & -0.012 & -0.032 & 0.004 & -0.013 & 0.001 \\
\hline$I D H P-I^{*}$ & -0.011 & 0.000 & -0.028 & 0.001 & 0.000 & 0.000 & -0.031 & 0.012 & & \\
\hline$I D H P-2 *$ & 0.318 & 0.004 & 0.003 & -0.003 & 1.000 & 0.033 & -0.038 & 0.007 & -0.020 & 0.002 \\
\hline$L A P^{*}$ & -0.006 & 0.006 & 0.001 & -0.001 & -0.003 & 0.003 & & & & \\
\hline$M D H-1^{*}$ & 0.496 & 0.007 & 0.653 & 0.040 & & & & & -0.009 & 0.003 \\
\hline$M E P^{*}$ & 0.000 & -0.002 & & & -0.001 & 0.001 & -0.011 & 0.004 & & \\
\hline$M P I-2 *$ & 0.014 & 0.005 & 0.000 & 0.000 & & & -0.029 & 0.006 & -0.009 & 0.003 \\
\hline$O P D H-2 *$ & 0.265 & -0.003 & & & -0.018 & 0.018 & -0.022 & 0.008 & 0.654 & 0.019 \\
\hline$O P D H-3 *$ & -0.013 & -0.003 & -0.049 & 0.047 & 0.002 & -0.002 & -0.014 & -0.009 & -0.013 & 0.005 \\
\hline$P E P A^{*}$ & -0.016 & -0.005 & 0.000 & -0.038 & -0.011 & -0.012 & -0.015 & 0.006 & -0.048 & 0.022 \\
\hline$P E P B^{*}$ & -0.006 & -0.003 & & & -0.006 & -0.010 & -0.024 & -0.015 & & \\
\hline$P E P D^{*}$ & -0.006 & -0.004 & 0.000 & -0.026 & -0.002 & 0.002 & -0.013 & 0.005 & -0.010 & 0.003 \\
\hline$P G D H^{*}$ & -0.017 & -0.002 & 0.000 & -0.017 & -0.058 & 0.055 & -0.039 & -0.009 & & \\
\hline$P G M^{*}$ & 0.185 & 0.001 & -0.066 & 0.021 & 0.197 & 0.028 & 0.321 & 0.001 & 0.065 & 0.015 \\
\hline Mean & 0.082 & 0.000 & 0.027 & 0.004 & 0.182 & 0.008 & 0.013 & 0.008 & 0.017 & 0.015 \\
\hline
\end{tabular}

two spring samples at $I D H P-2 *$ and $A L P D H^{*}$ loci, for the Iberian and Italian populations, respectively. However, such deviations were not significant after Bonferroni correction. The statistic $F_{\text {IS }}$ showed no significant variation for HW within samples where alleles were permuted among individuals (Table 3).

\section{Population differentiation}

Average $F_{\mathrm{ST}}$ values were generally low for the overall, geographic and temporal comparisons (Table 4). Hierarchical analysis of gene differentiation showed that $12 \%$ of total variance was accounted for by the combination of both geographic and temporal (seasons) factors. Population differentiation due to the geographic variance (Atlantic Iberian versus Italian samples) was the lowest $\left(F_{\mathrm{ST}}=0.000\right.$, Table 4). Nei's $(1987)$ unbiased $F$-statistic estimates $\left(F_{\mathrm{ST}}\right)$ showed variation at the loci $G 6 P D H^{*}$ $\left(F_{\mathrm{ST}}=0.004, P<0.05\right), M D H-1^{*} \quad\left(F_{\mathrm{ST}}=0.040, P<0.001\right)$, $P G H D^{*}\left(F_{\mathrm{ST}}=0.055, P<0.001\right)$ and $G 3 P D H^{*}\left(F_{\mathrm{ST}}=0.034\right.$, $P<0.001)$ after $\log$-likelihood $\mathrm{G}$-statistic testing within geographical, winter, spring and autumn comparisons, respectively (Table 4). For temporal testing adjustment of frequencies significance, a chi-squared test was applied (Workman \& Niswander, 1970), where temporal variation in allele frequencies significantly occurred in spring and autumn samples $\left(P G D H^{*}: \quad F_{\mathrm{ST}}=0.036, \quad \chi^{2}=14.76\right.$,
$P<0.005$ and, $G 3 P D H^{*}: F_{\mathrm{ST}}=0.038, \chi^{2}=13.45, P<0.005$; respectively).

Cavalli-Sforza \& Edward's (CSE) (1967) chord ( D $_{\text {cho }}$ ) genetic distances among samples were low $\left(\mathrm{D}_{\text {cho }}=0.063-\right.$ 0.101). The UPGMA analysis (after $\mathrm{D}_{\text {cho }}$ genetic distances) resulted in separating the summer and spring populations of Pisa and the Atlantic (IcPSum and IcWSp, respectively) from the bulk of the other six samples (Figure 1). Likely, MDS analysis together with the MST showed IcPSum, IcWSp and IcPW samples as the most genetically distant, with significant goodness of fit of $\mathrm{D}_{\text {cho }}$ values in the configuration space (0.05-0.10), which in turn showed dissimilarities among Illex coindetii samples in agreement with UPGMA results (Figure 2).

\section{DISCUSSION \\ Genetic variability}

Genetically low variable populations of Illex coindetii occurred at both Tyrrhenian and Atlantic locations and at the four seasons one-year round examined (see Table 3). Similar results were found in previous enzyme studies on I. argentinus possibly due to the type of genetic markers employed (Carvalho et al., 1992). General depressed variability seems to be present in cephalopods and mobile oceanic species, in contrast to other marine invertebrate organisms (Nevo, 1978). However, the presence of the moderately variable population of summer IcPSum at the 
northern Tyrrhenian could not be associated with previous analysis due to the lack of genetic seasonal studies. Thus, variability parameters might be likely to correlate with time and location, although very few studies have been done for both components along genetically diverse populations at large geographical scales (Fujio et al., 1983).

\section{Population differentiation}

General genetic uniformity of the widely separated samples of Illex coindetii off the northern Tyrrhenian and Iberian Atlantic waters was indicated from low $F_{\mathrm{ST}}$ values and genetic distances. This was not surprising where a homogeneous pattern of population structure has been found morphologically in I. coindetii at the eastern Atlantic for the whole-year round (Sánchez et al., 1998), and at the western Atlantic versus Mediterranean (Zecchini et al., 1996). In spite of the existence of few polymorphic enzyme loci (present study), the low levels of sample differentiation in $I$. coindetii and in other marine invertebrates are consistent with the occurrence of a large homogeneous population over extensive dispersal areas throughout the year (Dawe \& Brodziak, 1998). Nevertheless, some genetic variation was indicative in I. coindetii samples from the seasonal (up to $F_{\mathrm{ST}}=0.015$ ) but not geographic variable $\left(F_{\mathrm{ST}}=0.000\right.$, present study). A temporal differentiation pattern in other marine populations has seldom been analysed (Maltagliati \& Camilli, 2000), implying a conservative use of results interpretation for population structure conclusions (Waples, 1989). However, I. coindetii species have presented spawning peak activity that varied widely with areas and seasons along the Mediterranean and Atlantic (González \& Guerra, 1996; Sánchez et al., 1998), under the possibility of spawning stocks structure. Hierarchical analysis of gene differentiation had showed that $12 \%$ of total variance existed by the combination of both geographic and temporal (seasons) factors, possibly at the most distant samples of summer in Italy (IcPSum) and of spring in the Atlantic (IcWSp). Similarly, some loci variation had occurred at certain times of the year (Table 4). A temporal morphological comparison had been previously made in individuals from the northern Tyrrhenian and from the southern Tuscan archipelago, being summer specimens distinct from spring samples (Belcari, 1996). Thus, the latter ultimately may support the existence of two or more groups of $I$. coindetii with different growth rates that depended on the hatching season (Belcari, 1996; Sánchez et al., 1998), or on the hydrological characteristics (Hernández-García \& Castro, 1998). Thus, major maturation peaks in autumn and spring were revealed at the western Mediterranean (see Sánchez et al., 1998), which might correspond to the existence of different spawning groups. However, the slight genetic variation found for few loci in winter, spring and autumn, should not be indicative of population structuring (present study). From the UPGMA and MDS-MST results only the summer Italian $I$. coindetii IcPSum and spring Iberian IcWSp samples were genetically separated from the rest $(64 \%$ bootstrap at the UGMA, see Figures 1 \& 2). Previous genetic studies based on DNA techniques did not solve the population structure identification in its counterpart I. argentinus (Adcock et al., 1999). Furthermore, no consistent pattern of geographic or temporally based stock structure was apparent using microsatellite markers on the latter species (Adcock et al., 1999), which did not confirm previous suggestions of cryptic species or defined stocks at a microgeographic level (Carvalho et al., 1992). Within the Mediterranean teuthofauna, there is no evidence of isolation because of the large water inflow to the local basins and the uniformity of salinity and temperature along the water column. Our results suggest, in conclusion, the presence of a homogeneous population structure of the migrating $I$. coindetii individuals at least from the central Mediterranean to the Iberian Atlantic, the summer Italian and the spring Atlantic samples being the most divergent among the whole. Incipient temporal variation may be affecting the population structure of $I$. coindetii at some degree, being of interest for further molecular investigation of the species.

We wish to express our gratitude to Ferruccio Maltagliati for his valuable criticism and an anonymous referee; and to $\mathrm{M}$. Olveira for his help in obtaining the Atlantic samples at the Ribeira auction. P.M. received a University of Vigo Scholarship.

\section{REFERENCES}

Adcock, G.J., Shaw, P.W., Rodhouse, P.G. \& Carvalho, G.R., 1999. Microsatellite analysis of genetic diversity in the squid Illex argentinus during a period of intensive fishing. Marine Ecology Progress Series, 187, 171-178.

Belcari, P., 1996. Length-weight relationships in relation to sexual maturation of Illex coindetii (Cephalopoda: Ommastrephidae) in the northern Tyrrhenian Sea (Western Mediterranean). Scientia Marina, 60, 379-384.

Carvalho, G.R., Thompson, A. \& Stoner, A.L., 1992. Genetic diversity and population differentiation of the shortfin squid Illex argentinus in the south-west Atlantic. Fournal of Experimental Marine Biology and Ecology, 158, 105-121.

Cavalli-Sforza, L.L. \& Edwards, A.W.F., 1967. Phylogenetic analysis: models and estimation procedures. Evolution, 32, 550-570.

Dawe, E.G. \& Brodziak, J.K.T., 1998. Trophic relationships, ecosystem variability and recruitment. In Squid recruitment dynamics. The genus Illex as a model, the commercial Illex species and influences on variability (ed. P.G. Rodhouse et al.), pp. 125-156. Rome: FAO. [FAO Fisheries Technical Paper, no. 376.]

Felsenstein, J., 1993. PHYLIP. Phylogeny Inference Package, version $3.56 \mathrm{c}$, Seattle.

Fujio, Y., Yamanaka, R. \& Smith, P.J., 1983. Genetic variation in marine molluscs. Bulletin of the Fapanese Society of Scientific Fisheries, 49, 1089-1817.

González, A.F. \& Guerra, A., 1996. Reproductive biology of the short-finned squid Illex coindetii (Cephalopoda, Ommastrephidae) of the Northeastern Atlantic. Sarsia, 81, 107-118.

Goudet, J., 1995. FSTAT version 1.2: a computer program to calculate $F$-statistics. Fournal of Heredity, 86, 485-486.

Guo, S.W. \& Thompson, E.A., 1992. Performing the exact test of Hardy-Weinberg proportions for multiple alleles. Biometrics, 48, 361-372.

Harris, H. \& Hopkinson, D.A., 1976. Handbook of enzyme electrophoresis in human genetics. North-Holland: Amsterdam Academic Press.

Hernández-García, V. \& Castro, J.J., 1998. Morphological variability in Illex coindetii (Cephalopoda: Ommastrephidae) along the north-west coast of Africa. Fournal of the Marine Biological Association of the United Kingdom, 78, 1259-1268. 
IUBMB, 1992. International Union of Biochemistry and Molecular Biology. Enzyme Nomenclature 1992. San Diego, California: Academic Press.

Kruskal, J.B., 1964. Multidimensional scaling by optimizing goodness of fit to a nonmetric hypothesis. Psychometrika, 29, 1-27.

Maltagliati, F., Belcari, P., Casu D., Sartor, P., Vargiu, G. \& Castelli, A., 2002. Allozyme genetic variability and gene flow in Octopus vulgaris (Cephalopoda, Octopodidae) from the Mediterranean Sea. Bulletin of Marine Science, 71, 473-486.

Maltagliati, F. \& Camilli, L., 2000. Temporal genetic variation in a population of Aphanius fasciatus (Cyprinodontidae) from a brackish-water habitat at Elba Island (Italy). Environmental Biology of Fishes, 57, 107-112.

Moffett, I.J.J. \& Crozier, W.W., 1996. A study of temporal genetic variation in a natural population of Atlantic salmon in the River Bush, Northern Ireland. Fournal of Fish Biology, 48, 302-306.

Murphy, R.W., Sites, C.W., Jr, Buth, D.G. \& Haufler, C.H., 1996. Proteins: isozyme electroforesis. In Molecular systematics (ed. D.M. Hillis and C. Moritz), pp. 51-120. Sunderland, MA: Sinauer Associates.

Nei, M., 1987. Molecular evolutionary genetics. New York: Columbia University Press.

Nevo, E., 1978. Genetic variation in natural populations: patterns and theory. Theoretical Population Biology, 13, 121-177.

Rice, W.R., 1989. Analysing tables of statistical tests. Evolution, 43, 223-225.

Sánchez, P., González, A.F., Jereb, P., Laptikhovsky, V.V., Mangold, K.M., Nigmatullin, Ch.M. \& Ragonese, S., 1998. Illex coindetti. In Squid recruitment dynamics. The genus Illex as a model, the commercial Illex species and influences on variability (ed. P.G. Rodhouse et al.), pp. 59-76. Rome: FAO. [FAO Fisheries Technical Paper, no. 376.]
Sokal, R.R. \& Rohlf, F.J., 1981. Biometry. The principles and practice of statistics in biological research. New York: W.H. Freeman \& Co.

Waples, R.S., 1989. Temporal variation in allele frequencies: testing the right hypothesis. Evolution, 43, 1236-1251.

Waples, R.S. \& Teel, D.J., 1990. Conservation genetics of Pacific salmon. I. Temporal changes in allele frequency. Conservational Biology, 4, 144-156.

Workman, P.L. \& Niswander, J.D., 1970. Population studies on southwestern indian tribes. II. Local genetic differentiation in the Papago. American Fournal of Human Genetics, 22, 24-49.

Wright, S., 1978. Evolution and the genetics of populations. Variability within and among natural populations. Chicago, IL: University of Chicago Press.

Yeatman, J.A.H. \& Benzie, J.A.H., 1993. Cryptic speciation in Loligo from Northern Australia. In Recent advances in fishery biology (ed. T. Okutani et al.), pp. 641-652. Tokyo: Tokai University Press.

Zecchini, F., Vecchione, M. \& Roper, G.F.E., 1996. A quantitative comparison of hectocotylus morphology between Mediterranean and Western Atlantic populations of the squid Illex coindetii (Mollusca: Cephalopoda: Ommastrephidae). Proceedings of the Biological Society of Washington, 109, 591-599. 